(C) The Authors 2018. This is an Open Access article, distributed under the terms of the Creative Commons Attribution licence (http:// creativecommons.org/licenses/by/4.0/), which permits unrestricted reuse, distribution, and reproduction in any medium, provided the original work is properly cited.

\title{
Maternal protein intake during pregnancy is associated with child growth up to 5 years of age, but not through insulin-like growth factor-1: findings from the ROLO study
}

\author{
Aisling A. Geraghty ${ }^{1}$, Eileen C. O’Brien ${ }^{1}$, Goiuri Alberdi ${ }^{1}$, Mary K. Horan ${ }^{1}$, Jean Donnelly ${ }^{1}$, \\ Elizabeth Larkin ${ }^{1}$, Ricardo Segurado ${ }^{2}$, John Mehegan ${ }^{3}$, Eleanor J. Molloy ${ }^{4}$ and \\ Fionnuala M. McAuliffe ${ }^{1 *}$ \\ ${ }^{1}$ UCD Perinatal Research Centre, Obstetrics and Gynaecology, School of Medicine, University College Dublin, National \\ Maternity Hospital, Dublin, Republic of Ireland \\ ${ }^{2}$ Centre for Support and Training in Analysis and Research (CSTAR), School of Public Health, Physiotherapy and Sports \\ Science, University College Dublin, Dublin, Republic of Ireland \\ ${ }^{3}$ UCD School of Public Health, Physiotherapy and Sports Science, University College Dublin, Dublin 4, Republic of Ireland \\ ${ }^{4}$ Discipline of Paediatrics, Trinity College Dublin, Dublin, Republic of Ireland
}

(Submitted 8 August 2017 - Final revision received 18 July 2018 - Accepted 9 August 2018)

\section{Abstract}

Infant protein intake has been associated with child growth, however, research on maternal protein intake during pregnancy is limited. Insulin-like growth factors (IGF) play a role in early fetal development and maternal protein intake may influence child body composition via IGF-1. The aim of this study was to investigate the association of maternal protein intake throughout pregnancy on cord blood IGF-1 and child body composition from birth to 5 years of age. Analysis was carried out on 570 mother-child dyads from the Randomised cOntrol trial of LOw glycaemic index diet study. Protein intake was recorded using 3-d food diaries in each trimester of pregnancy and protein intake per kg of maternal weight ( $\mathrm{g} / \mathrm{d}$ per kg) was calculated. Cord blood IGF-1 was measured at birth. Infant anthropometry was measured at birth, 6 months, 2 and 5 years of age. Mixed modelling, linear regression, and mediation analysis were carried out. Birth weight centiles were positively associated with early-pregnancy protein intake $(\mathrm{g} / \mathrm{d}$ per $\mathrm{kg})$, while weight centiles from 6 months to 5 years were negatively associated $(B=-21 \cdot 6, P<0 \cdot 05)$. These associations were not mediated by IGF-1. Our findings suggest that high protein intake in early-pregnancy may exert an in utero effect on offspring body composition with a higher weight initially at birth but slower growth rates into childhood. Further research is needed to elucidate the exact mechanisms by which dietary protein modulates fetal growth.

Key words: Protein: Maternal diet: Pregnancy: Infant growth: Accelerated growth

The in utero environment influences fetal development and may have a lasting impact on offspring and their future disease risk $^{(1)}$. Nutrition during pregnancy and the maternal environment have been associated with altered body composition for the offspring at birth and offspring health later in life $e^{(2-4)}$. Inadequate energy or protein intakes in pregnancy have also been linked with increased risk of non-communicable diseases such as type 2 diabetes and obesity ${ }^{(5-7)}$.

There is an increased energy requirement in healthy pregnancies as basal metabolic rate and protein deposition increase $^{(8)}$. Additional dietary protein and amino acids are required to support the physiological changes necessary for the increase in maternal tissue and blood volume, alongside the development of fetal and placental tissue ${ }^{(9)}$. Total protein deposition over the course of pregnancy has been estimated at $611-925 \mathrm{~g}$, with an increase in the third trimester ${ }^{(8,10)}$. The Institute of Medicine (IOM) recommends that to support the deposition of the additional maternal, fetal and placental tissue, mothers require $0.8 \mathrm{~g}$ of protein/ $\mathrm{kg}$ of body weight per day in the first trimester of pregnancy, then $1.1 \mathrm{~g}$ of protein $/ \mathrm{kg}$ of body weight per day for the rest of pregnancy ${ }^{(11)}$. In well-nourished populations current intakes during pregnancy appear to be in line with these recommendations, however, research is limited as to what impact achieving these guidelines has on offspring growth and development ${ }^{(12-15)}$

Many reviews have examined the influence of energy and protein levels during pregnancy on birth outcomes ${ }^{(16-18)}$. A Cochrane review found that increased maternal protein intake

Abbreviation: IGF, insulin-like growth factor.

* Corresponding author: F. M. McAuliffe, fax +35316627586, email fionnuala.mcauliffe@ucd.ie 
resulted in increased birth weights, particularly in undernourished women, and increased head circumferences at birth $^{(18)}$. Balanced protein supplementation in pregnancy was also associated with increased birth weights and fewer smallfor-gestational age births, however, they concluded that impact of protein intake during pregnancy on the long-term growth and health of the offspring was uncertain and a paucity of knowledge in this area remains. Research to date has focused on early infancy protein intake and growth, with high protein intakes during infancy being associated with increased weight gain, adiposity and risk of obesity in later life ${ }^{(5,19-21)}$. However, these studies did not examine maternal dietary habits during pregnancy.

Intra-uterine exposures to maternal environmental factors, such as particular nutrient supplies, may induce a 'programming' effect on fetal metabolic systems. One potential mechanism through which maternal diet may influence infant body composition is through insulin-like growth factors (IGF). IGF-1 concentrations are influenced by dietary protein intakes in childhood and adulthood ${ }^{(19,22)}$. IGF-1 is thought to play a vital role in early fetal development with concentrations in cord blood being strongly associated with various measures of infant weight and adiposity ${ }^{(23)}$. Child IGF-1 concentrations have also previously been shown to influence growth velocity and catchup growth in infancy, particularly for low-birth weight infants $^{(24)}$, however there is a paucity of data relating to maternal dietary intakes during pregnancy and whether this may impact IGF-1 concentrations in the offspring.

We hypothesised maternal dietary protein intake during pregnancy influences child body composition through modulation of IGF-1. We aimed to examine the association of maternal dietary protein intake in trimesters 1,2 and 3 on child anthropometry at birth, 6 months, 2, and 5 years of age and investigate whether the effect was mediated via IGF-1 concentrations at birth.

\section{Methods}

\section{Study design}

Analysis was carried out on 570 mother-child pairs from the ROLO study (Randomised cOntrol trial of LOw glycaemic index diet in pregnancy to prevent recurrence of macrosomia) ${ }^{(25)}$. This study was carried out in the National Maternity Hospital, Dublin, with institutional ethical approval and written maternal consent, in accordance with the Helsinki Declaration of 1975 as revised in 1983. The Clinical trial registry no. is ISRCTN54392969 (http:// www.isrctn.com/). This study involved 800 secundigravida women who had previously given birth to a macrosomic infant (birth weight $>4 \mathrm{~kg}$ ). Women were recruited who were $<18$ weeks' gestation with a singleton pregnancy, had no previous history of gestational diabetes, nor were taking any medication, and aged over 18 years. The women were randomised into either the control arm ( $n$ 400), which was routine antenatal care, or the intervention which was dietary advice to follow a low glycaemic index diet $(n$ 400). Detailed methods and results have been previously published ${ }^{(25-27)}$. In brief, the intervention did not influence birth weight, the primary outcome, however, it did benefit the mothers in terms of having lower gestational weight gain and improving glucose tolerance when compared with mothers in the control group ${ }^{(25)}$. The intervention also impacted the mothers' dietary intakes resulting in lower energy intakes $(P<0 \cdot 05)$, higher protein as a percentage of energy $(P<0.01)$ and higher dietary fibre intake $(P<0.01)$ postintervention $^{(28)}$.

\section{Data collection}

Anthropometry and body composition. Women were recruited at their first antenatal visit (12.8 weeks' gestation $( \pm 2 \cdot 3$ weeks $)$ ) and had their height and weight measured by the research team. Participant weight was recorded to the nearest $0 \cdot 1 \mathrm{~kg}$ and height was measured using a wall-mounted stadiometer to the nearest $0 \cdot 1 \mathrm{~cm}$. BMI was calculated $\left(\mathrm{kg} / \mathrm{m}^{2}\right)$. At birth, infant recumbent length $(\mathrm{cm})$ and weight $(\mathrm{kg})$ were measured along with abdominal circumference $(\mathrm{cm})$ and skinfold thickness of biceps, triceps, subscapular and thigh ( $\mathrm{mm})$. The women were then asked to participate in follow-up visits when their child was 6 months, 2 and 5 years of age. In this analysis, 253 participants were followed-up at 6 months, 288 at 2 years and 327 at 5 years. Again, weight and length were measured (recumbent length at 6 months and 2 years, standing height at 5 years), and abdominal circumference $(\mathrm{cm})$ and skinfold thicknesses (bicep, tricep, subscapular and thigh, in $\mathrm{mm}$ ) were taken. Weight and BMI values were converted to centiles, relative to 1990 UK reference data using the Excel LMS Growth macro ${ }^{(29,30)}$, to control for sex and age differences in the children, and ratios for waist: length and subscapular:tricep, sum of skinfold measurements and sum of tricep and subscapular skinfold measurements were calculated.

\section{Demographics and dietary data}

The mothers completed demographic, health and lifestyle questionnaires after their first booking visit in the hospital. In all, 3-d food diaries were completed during each trimester of pregnancy, one before the intervention and two after, to estimate dietary intake throughout the pregnancy. Total absolute dietary protein intake $(\mathrm{g} / \mathrm{d})$ was calculated for each trimester using nutritional analysis software NetWISP version 3.0 (Tinuviel Software). This software utilises the food composition database from the sixth edition of McCance and Widdowson's food composition tables. Percentage of energy coming from protein (Pro\%Energy) was calculated from this to estimate the proportion of protein in the diet and to control for energy intake. As protein recommendations are based on individual weight, we calculated protein intake per kg of early-pregnancy body weight ( $\mathrm{g} / \mathrm{d}$ per $\mathrm{kg}$ ) for each trimester of pregnancy. At the 6 months, 2- and 5-year follow-up appointments mothers completed a lifestyle questionnaire which asked about breastfeeding status. Breastfeeding was assessed as the child had ever been breastfed. To increase statistical power this information was dichotomised into the infant having ever breastfed or not. 


\section{Laboratory analyses}

A cord blood serum sample was collected at delivery and stored at $-80^{\circ} \mathrm{C}$ until batch analysis. IGF-1 was calculated by multianalyte profiling performed on the Luminex Mag-pix System (Luminex Corporation) in accordance with the manufacturer's instructions. The techniques and the laboratory that carried out these analyses were calibrated to National Institute of Standards in Technology reference materials.

\section{Statistical analyses}

All variables were assessed for normality by visual analysis of histograms and normal $P-P$ plots. Relationships between the central tendencies for protein intake between trimester 1 and trimesters 2 and 3 of pregnancy were examined using paired sample $t$ tests and intakes between the control and intervention groups were examined using independent sample $t$ tests. Linear mixed-effects modelling (SPSS procedure MIXED) was carried out to examine the association between maternal dietary protein intake and the longitudinal child anthropometry measurements from birth up to 5 years of age. Using protein intake - child age interaction terms we investigated associations of maternal protein intakes with changes in child body composition from birth to 6 months, 2 and 5 years of age. These models were adjusted for membership of the intervention group, maternal BMI during pregnancy, maternal education level, sex of the child and gestational age. Models with a $P<0.05$ were considered significant and were then used to create multiple regression models separately for each outcome of child anthropometry (at the significant age). In the linear regression models, we uniformly adjusted for the following set of potential confounders; at birth we controlled for membership of the intervention group, maternal early-pregnancy BMI, gestational age, infant sex, maternal education level and maternal smoking during pregnancy. At 6 months, 2 and 5-years of age we controlled for the measurement at birth, membership of the intervention group, child sex, age at data collection, maternal education level and breastfeeding. Longitudinal line plots were created using the ggplot 2 package for $\mathrm{R}$ for visual display of the unadjusted associations between trimester one protein $(\mathrm{g} / \mathrm{d}$ per $\mathrm{kg}$ ) intake and child weight and length over time.

Student's $t$ tests for normally distributed data or MannWhitney $U$ tests for non-normally distributed data were used to examine differences in offspring weight centiles and length in mothers meeting the dietary recommendations for protein intakes during pregnancy compared with those who were not meeting the recommended intakes. Pearson correlation was used for normally distributed data, with Spearman's correlation for non-normally distributed data, to measure the correlation between IGF-1 and each estimate of dietary protein intake in each trimester in pregnancy. Similarly, correlations were also measured between IGF-1 and each anthropometric measures of child weight and adiposity (at birth, 6 months, 2 and 5 years of age). Bivariate associations of $P<0.05$ were considered significant. Mediation analysis of IGF-1 mediating the association between maternal protein intake and child body composition was carried out using PROCESS ${ }^{(31)}$. A sensitivity analysis was carried out where participants were assessed for underreporting of energy intakes, classified as a cut-off of 0.9 using the Goldberg method ${ }^{(32)}$ which has been used previously in pregnant populations ${ }^{(33)}$. The participants identified as potentialunderreporters were excluded from the analysis and the multiple regression models were run again to detect any differences. All statistical analyses were carried out using R and SPSS (Statistical Package for the Social Sciences) software version 24.0 (IBM).

\section{Results}

\section{Cohort characteristics}

The mothers in this analysis were predominately Caucasian, highly educated, and had a mean BMI of 26.4 in early pregnancy, which is in the overweight category (Table 1). Both absolute protein intake and protein adjusted for maternal weight $(\mathrm{g} / \mathrm{d}$ and $\mathrm{g} / \mathrm{d}$ per $\mathrm{kg}$ ) increased significantly from early pregnancy (trimester 1$)$ to $\mathrm{mid} /$ late pregnancy $(P<0 \cdot 05)$. The percentage of energy coming from protein did not change over the course of pregnancy in this cohort. There were no differences in absolute or weight-adjusted protein intake between the ROLO intervention and control groups, however protein as a percentage of energy was increased in the intervention group in both trimester $2(17.8 v .16 .8 \%, P<0.001)$ and trimester $3(17.6 v .16 .7 \%$, $P<0.001)$. The mean birth weight of the children was $4.02 \mathrm{~kg}$, which is in the macrosomic range, and the mean birth weight centile was 72.7 (Table 2). The weight centiles were lower at subsequent ages compared with birth, with a mean weight centile of 63.3 at 6 months, 62.55 at 2 years and 63.6 at 5 years of age. There was a significant difference in weight between males and females up to 2 years of age with males being consistently heavier $(P<0 \cdot 001)$.

\section{Mixed-effects modelling}

The linear mixed-effects models identified associations between maternal protein intakes during pregnancy, and offspring weight and adiposity measures at birth, and changes from birth to later ages (Table 3). Protein as a percentage of energy intake was not associated with offspring anthropometry at any age $(P>0.05)$. Maternal protein intake adjusted for maternal weight $(\mathrm{g} / \mathrm{d}$ per $\mathrm{kg})$ appeared to primarily predict the changes in child growth and adiposity. Weight centile was negatively associated with weight-adjusted trimester 1 intake of protein $(\mathrm{g} / \mathrm{d}$ per $\mathrm{kg}$ ) at 6 months, 2 and 5 years of age, and negatively with trimesters 2 and 3 protein intakes at 2 and 5 years, however birth weight centile was positively associated with trimester 2 protein intake $(P<0.05$, Tables 3 and 4$)$.

Unadjusted associations of trimester 1 weight-adjusted protein intake with child weight centile trajectories are displayed in Fig. 1, showing a positive association at birth but negative at 6 months, 2 and 5 years (Fig. 1). Unadjusted associations of trimester 1 weight-adjusted protein intake with child length trajectories shows a negative relationship from birth up to 5 years of age (Fig. 2). 
Table 1. Characteristics of the Randomised cOntrol trial of LOw glycaemic index diet mothers and dietary protein during pregnancy ( $n$ 570) (Mean values and standard deviations; numbers and percentages)

\begin{tabular}{|c|c|c|c|c|c|c|}
\hline & Mean & SD & Mean & SD & Mean & SD \\
\hline \multicolumn{7}{|l|}{ Characteristics of mothers during pregnancy } \\
\hline \\
\hline$n$ & \multicolumn{2}{|c|}{257} & & & & \\
\hline$\%$ & \multicolumn{2}{|c|}{$45 \cdot 1$} & & & & \\
\hline Mother age at delivery (years) & 32.77 & 4.0 & & & & \\
\hline Mother height $(\mathrm{cm})$ & $165 \cdot 89$ & $6 \cdot 2$ & & & & \\
\hline Mother weight (13 weeks' gestation, kg) & 72.71 & $13 \cdot 3$ & & & & \\
\hline Maternal BMI (13 weeks' gestation, $\mathrm{kg} / \mathrm{m}^{2}$ ) & 26.42 & 4.5 & & & & \\
\hline \multicolumn{7}{|l|}{ Maternal BMI category (13 weeks' gestation) } \\
\hline \multicolumn{7}{|l|}{ Normal $\left(18.5-24.9 \mathrm{~kg} / \mathrm{m}^{2}\right)$} \\
\hline$n$ & \multicolumn{2}{|c|}{249} & & & & \\
\hline$\%$ & \multicolumn{2}{|c|}{$43 \cdot 8$} & & & & \\
\hline Overweight $\left(25-29.9 \mathrm{~kg} / \mathrm{m}^{2}\right)$ & & & & & & \\
\hline$n$ & \multicolumn{2}{|c|}{223} & & & & \\
\hline$\%$ & \multicolumn{2}{|c|}{$39 \cdot 3$} & & & & \\
\hline Obese $\left(>30 \mathrm{~kg} / \mathrm{m}^{2}\right)$ & & & & & & \\
\hline$n$ & \multirow{2}{*}{\multicolumn{2}{|c|}{$\begin{array}{c}96 \\
16.9\end{array}$}} & & & & \\
\hline$\%$ & & & & & & \\
\hline \multicolumn{7}{|l|}{ Education status (third level)* } \\
\hline$n$ & \multirow{2}{*}{\multicolumn{2}{|c|}{$\begin{array}{c}302 \\
55.3\end{array}$}} & & & & \\
\hline$\%$ & & & & & & \\
\hline \multicolumn{7}{|l|}{ Ethnicity: Caucasian } \\
\hline$n$ & \multirow{2}{*}{\multicolumn{2}{|c|}{$\begin{array}{l}558 \\
97.9\end{array}$}} & & & & \\
\hline$\%$ & & & & & & \\
\hline \multicolumn{7}{|l|}{ Smoking during pregnancy } \\
\hline$n$ & \multirow{2}{*}{\multicolumn{2}{|c|}{$\begin{array}{l}20 \\
3.5\end{array}$}} & & & & \\
\hline$\%$ & & & & & & \\
\hline \multirow[t]{2}{*}{ Gestational weight gain $(\mathrm{kg}) \dagger$} & $13 \cdot 12$ & $4 \cdot 3$ & & & & \\
\hline & \multicolumn{2}{|c|}{ Trimester 1} & \multicolumn{2}{|c|}{ Trimester 2} & \multicolumn{2}{|c|}{ Trimester 3} \\
\hline \multicolumn{7}{|l|}{ Dietary intakes } \\
\hline Energy $(\mathrm{kJ} / \mathrm{d})$ & 7743.96 & $1851 \cdot 84$ & 7855.54 & 1954.76 & $7909 \cdot 27$ & $1899 \cdot 12$ \\
\hline Energy $(\mathrm{kcal} / \mathrm{d})$ & $1850 \cdot 85$ & $442 \cdot 6$ & 1877.52 & $467 \cdot 2$ & $1890 \cdot 36$ & 453.9 \\
\hline Absolute protein $(\mathrm{g} / \mathrm{d})$ & 77.84 & 19.6 & 79.60 & 19.4 & 79.73 & $19 \cdot 7$ \\
\hline Energy-adjusted protein (\% of energy) & 17.01 & 3.1 & $17 \cdot 22$ & 3.1 & $17 \cdot 10$ & $3 \cdot 1$ \\
\hline Weight-adjusted protein ( $\mathrm{g} / \mathrm{d}$ per $\mathrm{kg}$ ) & $1 \cdot 11$ & 0.3 & $1 \cdot 13$ & 0.3 & $1 \cdot 14$ & 0.4 \\
\hline Carbohydrates (g/d) & 231.82 & 60.8 & 231.30 & 61.5 & 233.76 & $59 \cdot 8$ \\
\hline Total fat $(\mathrm{g} / \mathrm{d})$ & 74.06 & $23 \cdot 3$ & 76.47 & $25 \cdot 0$ & $76 \cdot 71$ & $24 \cdot 3$ \\
\hline
\end{tabular}

$\mathrm{RCT}$, randomised control trial.

* Third level education: education from a higher education institute (universities, institutes of technology and colleges of education).

$\dagger$ Gestational weight gain was calculated as weight gained from the first booking visiting (13 weeks' gestation) until week 38 .

\section{Multiple-regression}

All multiple regression models are reported in Table 5. Early pregnancy weight-adjusted protein intake was negatively associated with child weight at 5 years of age with a $0.5 \mathrm{~g} / \mathrm{d}$ per $\mathrm{kg}$ increase in protein in trimester 1 predicting a decrease of $10 \cdot 82$ in weight centile at 5 years. No other associations as identified by the mixed-effects modelling remained significant.

\section{Adherence to current dietary protein guidelines}

We examined the differences in child weight and length between those born to mothers meeting the IOM recommendations of $0.8 \mathrm{~g} / \mathrm{d}$ per $\mathrm{kg}$ in trimester 1 and $1.1 \mathrm{~g} / \mathrm{d}$ per $\mathrm{kg}$ in trimesters 2 and 3 of pregnancy (online Supplementary Table $\mathrm{S} 1)$. In trimester $183 \%$ were consuming $0.8 \mathrm{~g} / \mathrm{d}$ per kg or more, $50.9 \%$ were consuming the recommended $1.1 \mathrm{~g} / \mathrm{d}$ per $\mathrm{kg}$ in trimester 2 , and $51.7 \%$ in trimester 3 . We found that infants born to mothers who were meeting the recommendations for protein intake in trimesters 2 and 3 of pregnancy had a higher centile for birth weight (83.0 v. 74.9 in trimester 2 and $80.8 v .76 .8$ in trimester $3, P<0.01$ for both) while weight centiles at 6 months, 2 and 5 years were all lower in children whose mothers met the recommendations (online Supplementary Table S1). While no difference was seen at birth, length was lower at the subsequent ages in children whose mothers met the recommended $1 \cdot 1 \mathrm{~g} / \mathrm{d} \cdot \mathrm{kg}$ (online Supplementary Table S1).

\section{Insulin-like growth factor-1}

Mean cord blood IGF-1 concentration was $113.4 \mathrm{ng} / \mathrm{ml}$ (sD 37-3). IGF-1 concentration was not significantly associated with any measure of maternal protein intake during pregnancy $(P>0.05$ for all). IGF-1 concentration was positively associated with birth weight centile (Pearson correlation $=0.331$, $P<0.001$ ), birth waist:height ratio (Pearson correlation = $0 \cdot 272, P=0 \cdot 012$ ), birth abdominal circumference (Pearson 
correlation $=0 \cdot 252, P=0 \cdot 012$ ) and sum of skinfolds (Pearson correlation $=0.276, \quad P=0 \cdot 013$ ). IGF-1 was also positively associated with sum of skinfolds at 6 months (Pearson correlation $=225, P=0.034)$ and negatively with height at 5 years of age $($ Pearson correlation $=-0 \cdot 186, P=0 \cdot 025)$. IGF-1 was not associated with child weight, height or body composition at any other age. Mediation analysis found that $<1 \%$ of the variance in child body measurements was explained by maternal protein intake in pregnancy via an indirect IGF-1 mediation $(P>0.05)$.

\section{Underreporters}

Using the Goldberg ratio of below $0.9,9.9 \%$ of participants were classified as under-reporters in trimester 1 and $10.5 \%$ in trimester 2 . Re-running the regression analysis excluding these potential under-reporters had no effect on the significance of any of the models or a significant impact on the effect estimate (data not shown), so results for the full cohort were reported in this paper.

\section{Discussion}

\section{Main findings}

In this cohort, we identified a relationship with weightadjusted maternal protein intake $(\mathrm{g} / \mathrm{d}$ per $\mathrm{kg}$ ) in early- and mid-pregnancy and changes in child weight from birth up to 5 years of age. We found no associations between the proportion of energy coming from protein during pregnancy and child growth or body composition. IGF-1 concentration was not associated with maternal protein intakes and did not mediate any of these associations with later child body composition.

Associations with protein intake have been reported in previous studies, with higher protein and energy during pregnancy leading to higher birth weight ${ }^{(18)}$, however, the relationship between early pregnancy weight-adjusted protein intake and weight centiles is quite novel. We found that higher weightadjusted protein intakes in early- and mid-pregnancy may result in a higher birth weight centile initially but a reduction in weight as the child ages. This suggests that higher protein intakes in early pregnancy may result in high rates of fetal growth in utero but less accelerated growth in early childhood. These findings are corroborated by results recently published from project Viva in the USA ${ }^{(34)}$. Taking the same approach of categorising protein intake in $\mathrm{g} / \mathrm{kg}$ of maternal weight, they found higher protein intake in early- and mid-pregnancy were associated with slower growth into childhood. They concluded that high protein intakes during pregnancy did not increase child growth and may even reduce it. In contrast to our findings, a study carried out in Australia found that higher absolute protein in the third trimester was associated with lower birth weights and lower ponderal index in large birth weight infants only ${ }^{(35)}$. They also associated an increase in the percentage of energy from protein in trimester 3 with lower birth weights, however, after adjusting our models for confounders, we found no associations with child body composition and percentage of energy coming from 
Table 3. Mixed model coefficients for the effects of maternal protein intake at birth and changes in child weight, length, waist:height ratio and BMI up to 5 years of age $\dagger$

( $B$ coefficients and $95 \%$ confidence intervals)

\begin{tabular}{|c|c|c|c|c|c|c|c|c|}
\hline & \multicolumn{2}{|r|}{ Birth } & \multicolumn{2}{|c|}{$\Delta$ Birth to 6 months } & \multicolumn{2}{|c|}{$\Delta$ Birth to 2 years } & \multicolumn{2}{|c|}{$\Delta$ Birth to 5 years } \\
\hline & $B$ & $95 \% \mathrm{Cl}$ & $B$ & $95 \% \mathrm{Cl}$ & $B$ & $95 \% \mathrm{Cl}$ & $B$ & $95 \% \mathrm{Cl}$ \\
\hline \multicolumn{9}{|l|}{ Weight centile } \\
\hline T1 weight-adjusted protein ( $\mathrm{g} / \mathrm{d}$ per $\mathrm{kg}$ ) & $7 \cdot 45$ & $-0.11,15.01$ & -15.08 & $-26 \cdot 70,-3 \cdot 46$ & $-15 \cdot 08^{*}$ & $-24.74,-5.43$ & $-17 \cdot 06^{\star}$ & $-24.81,-9.32$ \\
\hline T2 weight-adjusted protein ( $\mathrm{g} / \mathrm{d}$ per $\mathrm{kg})$ & $11 \cdot 07^{\star}$ & $3.60,18.55$ & $-11 \cdot 23$ & $-22.75,0.29$ & $-15 \cdot 05^{\star}$ & $-24 \cdot 79,-5 \cdot 31$ & $-11 \cdot 75^{\star}$ & $-19.43,-4.08$ \\
\hline T3 weight-adjusted protein $(\mathrm{g} / \mathrm{d}$ per $\mathrm{kg}$ ) & $4 \cdot 61$ & $-3 \cdot 01,12 \cdot 24$ & $-6 \cdot 12$ & $-17 \cdot 17,4.92$ & $-13 \cdot 68^{\star}$ & $-23 \cdot 27,-4 \cdot 10$ & $-11 \cdot 81^{*}$ & $-19.69,-3.93$ \\
\hline \multicolumn{9}{|l|}{ Length $(\mathrm{cm})$} \\
\hline T1 weight-adjusted protein ( $\mathrm{g} / \mathrm{d}$ per $\mathrm{kg}$ ) & 0.13 & $-0.59,0.84$ & -0.14 & $-1 \cdot 35,1.08$ & -1.00 & $-2 \cdot 14,0 \cdot 14$ & -0.56 & $-1.84,0.72$ \\
\hline $\mathrm{T} 2$ weight-adjusted protein ( $\mathrm{g} / \mathrm{d}$ per $\mathrm{kg}$ ) & 0.60 & $-0.12,1.32$ & -0.25 & $-1.46,0.95$ & $-0 \cdot 30$ & $-1.48,0.89$ & 0.40 & $-0.89,1.69$ \\
\hline T3 weight-adjusted protein ( $\mathrm{g} / \mathrm{d}$ per $\mathrm{kg})$ & 0.15 & $-0.59,0.88$ & -0.43 & $-1.59,0.73$ & -0.97 & $-2 \cdot 14,0.20$ & -0.45 & $-1.78,0.88$ \\
\hline \multicolumn{9}{|l|}{ Waist:height ratio } \\
\hline T1 weight-adjusted protein ( $\mathrm{g} / \mathrm{d}$ per $\mathrm{kg}$ ) & 0.00 & $-0.02,0.03$ & 0.01 & $-0.01,0.03$ & 0.01 & $-0.01,0.04$ & -0.00 & $-0.02,0.02$ \\
\hline T2 weight-adjusted protein ( $\mathrm{g} / \mathrm{d}$ per $\mathrm{kg}$ ) & 0.01 & $-0.01,0.03$ & -0.00 & $-0.03,0.02$ & -0.00 & $-0.03,0.02$ & -0.01 & $-0.03,0.02$ \\
\hline T3 weight-adjusted protein ( $\mathrm{g} / \mathrm{d}$ per $\mathrm{kg}$ ) & 0.01 & $-0.01,0.03$ & -0.00 & $-0.2,0.02$ & 0.00 & $-0.02,0.03$ & -0.00 & $-0.2,0.02$ \\
\hline BMI centileł & & & 6 months & & $\Delta 6$ mont & $s$ to 2 years & $\Delta 6$ mont & $s$ to 5 years \\
\hline $\mathrm{T} 1$ weight-adjusted protein $(\mathrm{g} / \mathrm{d}$ per $\mathrm{kg}$ ) & & - & $-2 \cdot 37$ & $-15 \cdot 32,10 \cdot 58$ & $4 \cdot 70$ & $-9.43,18.84$ & -5.00 & $-16 \cdot 55,6 \cdot 55$ \\
\hline $\mathrm{T} 2$ weight-adjusted protein ( $\mathrm{g} / \mathrm{d}$ per $\mathrm{kg}$ ) & & - & $7 \cdot 25$ & $-5.54,20.04$ & -1.72 & $-15 \cdot 90,12 \cdot 46$ & $-4 \cdot 64$ & $-16 \cdot 30,7 \cdot 01$ \\
\hline T3 weight-adjusted protein ( $\mathrm{g} / \mathrm{d}$ per $\mathrm{kg})$ & & - & 4.52 & $-7 \cdot 93,16.97$ & $-2 \cdot 37$ & $-16.05,11.31$ & $-7 \cdot 82$ & $-18 \cdot 85,3 \cdot 20$ \\
\hline
\end{tabular}

T1, trimester 1; T2, trimester 2; T3, trimester 3; $\Delta$, change over the specified time period.

* $P<0.05$.

$\dagger$ All models were adjusted for membership of the intervention group, maternal BMI during pregnancy, maternal education level, sex of the child, and gestational age.

$\ddagger$ BMI centile was just calculated at the 6-month, and 2- and 5-year time points.

Table 4. Mixed model coefficients for the effects of maternal protein intake at birth and changes in child circumferences and skinfold measures up to 5 years of age $\dagger$

( $B$ coefficients and $95 \%$ confidence intervals)

\begin{tabular}{|c|c|c|c|c|c|c|c|c|}
\hline & \multicolumn{2}{|c|}{ Birth } & \multicolumn{2}{|c|}{$\Delta$ Birth to 6 months } & \multicolumn{2}{|c|}{$\Delta$ Birth to 2 years } & \multicolumn{2}{|c|}{$\Delta$ Birth to 5 years } \\
\hline & $B$ & $95 \% \mathrm{Cl}$ & $B$ & $95 \% \mathrm{Cl}$ & $B$ & $95 \% \mathrm{Cl}$ & $B$ & $95 \% \mathrm{Cl}$ \\
\hline \multicolumn{9}{|l|}{ Chest circumference $(\mathrm{cm})$} \\
\hline $\mathrm{T} 1$ weight-adjusted protein (g/d per kg) & -0.33 & $-1.55,0.88$ & 1.58 & $-0.50,3.65$ & 0.67 & $-0.81,2 \cdot 15$ & -0.56 & $-1.88,0.77$ \\
\hline T2 weight-adjusted protein ( $\mathrm{g} / \mathrm{d}$ per $\mathrm{kg}$ ) & 0.14 & $-1.04,1.31$ & 0.73 & $-1 \cdot 30,2 \cdot 76$ & -0.30 & $-1 \cdot 77,1 \cdot 17$ & -0.83 & $-2.11,0.46$ \\
\hline T3 weight-adjusted protein (g/d per kg) & -0.07 & $-1.22,1.07$ & 1.04 & $-0.89,2.96$ & 0.40 & $-1.02,1.82$ & -0.63 & $-1.89,0.62$ \\
\hline \multicolumn{9}{|l|}{ Abdominal circumference $(\mathrm{cm})$} \\
\hline T1 weight-adjusted protein (g/d per kg) & -0.03 & $-1.00,0.94$ & 0.63 & $-0.48,1.74$ & 0.55 & $-1 \cdot 04,2 \cdot 13$ & -0.68 & $-2 \cdot 19,0.84$ \\
\hline T2 weight-adjusted protein (g/d per kg) & 0.50 & $-0.43,1.43$ & -0.30 & $-1.38,0.78$ & -0.38 & $-1.97,1.21$ & -0.36 & $-1 \cdot 82,1 \cdot 11$ \\
\hline T3 weight-adjusted protein ( $\mathrm{g} / \mathrm{d}$ per $\mathrm{kg})$ & 0.31 & $-0.60,1.21$ & -0.04 & $-1.08,0.99$ & $0 \cdot 12$ & $-1.41,1.67$ & 0.08 & $-1.40,1.57$ \\
\hline \multicolumn{9}{|l|}{ Sum of skinfolds $(\mathrm{mm})$} \\
\hline $\mathrm{T} 1$ weight-adjusted protein ( $\mathrm{g} / \mathrm{d}$ per $\mathrm{kg}$ ) & 1.22 & $-1.34,3.79$ & -0.06 & $-3.16,3.03$ & -0.29 & $-3.48,2.89$ & $-4 \cdot 14^{\star}$ & $-8.08,-0.19$ \\
\hline T2 weight-adjusted protein (g/d per kg) & -0.76 & $-3.02,3.25$ & 0.12 & $-3.02,3.25$ & -0.27 & $-3.44,2.90$ & $-2 \cdot 75$ & $-6.53,1.04$ \\
\hline T3 weight-adjusted protein ( $\mathrm{g} / \mathrm{d}$ per $\mathrm{kg}$ ) & 0.88 & $-1.64,3.39$ & -0.88 & $-3 \cdot 86,2 \cdot 11$ & -0.44 & $-3.59,2.71$ & -2.91 & $-6.79,0.98$ \\
\hline \multicolumn{9}{|l|}{ Subscapular:tricep skinfold ratio } \\
\hline T1 weight-adjusted protein (g/d per kg) & -0.04 & $-0.13,0.05$ & 0.01 & $-0.20,0.23$ & -0.06 & $-0.37,0.24$ & 0.02 & $-0.08,0.13$ \\
\hline T2 weight-adjusted protein ( $\mathrm{g} / \mathrm{d}$ per $\mathrm{kg}$ ) & 0.01 & $-0.07,0.10$ & 0.09 & $-0.13,0.32$ & -0.14 & $-0.45,0.17$ & -0.05 & $-0.16,0.05$ \\
\hline T3 weight-adjusted protein ( $\mathrm{g} / \mathrm{d}$ per $\mathrm{kg})$ & -0.01 & $-0.10,0.08$ & -0.03 & $-0.24,0.18$ & -0.13 & $-0.44,0.18$ & 0.00 & $-0.97,0.10$ \\
\hline
\end{tabular}

T1, trimester 1 ; T2, trimester 2; T3, trimester 3; $\Delta$, change over the specified time period.

${ }^{*} P<0.05$.

† All models were adjusted for membership of the intervention group, maternal BMI during pregnancy, maternal education level, sex of the child, and gestational age.

protein. These results highlight the potential differences in the timing of nutrient exposure during pregnancy. Our results suggest that protein intakes in early- and mid-pregnancy may induce a programming effect on later child growth, while results from other studies suggest that protein intakes in late pregnancy have a more direct effect on child body composition at birth.

An Indian study examined maternal intakes of milk and protein during pregnancy and found that in utero fetal growth rates were influenced by protein intake ${ }^{(36)}$. They reported offspring of mothers consuming 50-70 g protein/d had higher abdominal circumference, femur length and head circumference between 16 and 38 weeks' gestation. Although average absolute protein intakes in this cohort were $63.3 \mathrm{~g} / \mathrm{d}$ (with the percentage of energy coming from protein at approximately $12.7 \%$ ), which was slightly lower than our cohort, these findings are in line with our results of higher protein intake leading to higher birth weight centiles. The influence of child sex is important as there was a significant difference in weight with males being born heavier and remaining heavier than females up to 2 years of age in this 


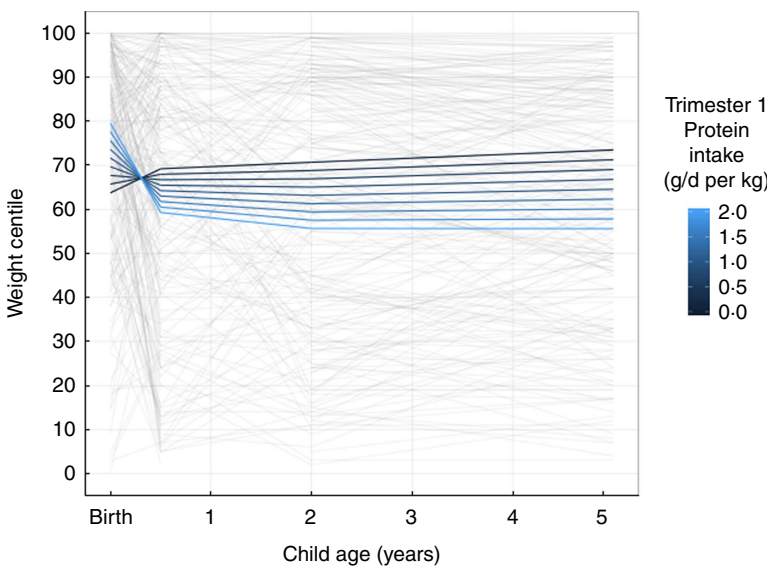

Fig. 1. Longitudinal line plot displaying unadjusted relationship of maternal protein intake and child weight centile trajectories from birth to 5 years of age. Grey lines display individual participant values and their change over time from birth to 6 months, 2 and 5 years of age; coloured lines indicate estimated marginal means predicted based on the indicated protein intakes in the first trimester of pregnancy.

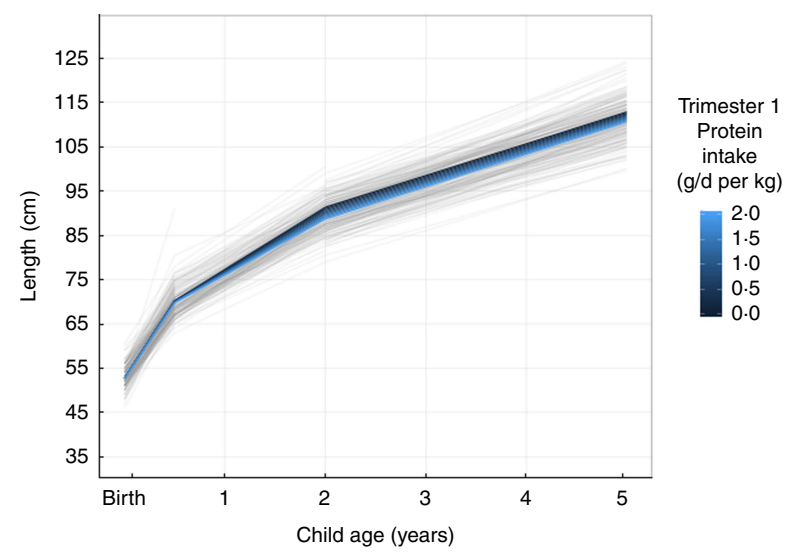

Fig. 2. Longitudinal line plot displaying unadjusted relationship of maternal protein intake and child length trajectories from birth to 5 years of age. Grey lines display individual participant values and their change over time from birth to 6 months, 2 and 5 years of age; coloured lines indicate estimated marginal means predicted based on the indicated protein intakes in the first trimester of pregnancy.

cohort. Weight centiles take child age and sex into account and this positive association with maternal protein intake remained after controlling for additional confounders. In addition, a study carried out in the Netherlands reported that after controlling for socioeconomic factors, higher maternal protein intakes were associated with higher lean body mass, but not fat mass or $\mathrm{BMI}^{(37)}$. While we found associations with maternal protein intake and birth weight centiles, we found no association with offspring BMI or skinfolds, which potentially could indicate that this association may be due to changes in offspring lean body mass.

High weight gain in the first 2 years of childhood has been shown to result in a higher BMI later in life $e^{(5)}$. Accelerated catch-up growth in early childhood has been associated with increased risk of adverse health and cardiovascular events in later life $\mathrm{e}^{(38,39)}$. Greater weight gain from birth during infancy has also been associated with increased fat mass and central fat distribution ${ }^{(39)}$. With rapid weight gain in infancy being a risk factor for increased adiposity and adverse health in later life, this slowed growth identified with higher protein intakes during pregnancy may be beneficial for the offspring.

In line with previous research ${ }^{(23)}$, we also found IGF-1 concentration in cord blood was associated with various measures of infant weight and adiposity up to 6 months of age in our cohort. While the research on protein intakes in infancy modulating IGF-1 concentration is quite clear, we found no link between maternal protein intakes and IGF-1 concentration in cord blood. To our knowledge, we are one of the first studies to report that the associations between maternal protein intakes and the resulting child body composition were not mediated by IGF-1 and the mechanism behind these relationships remain unclear. Previously, it was suggested that higher protein diets may result in lean mass sparing and improved glycaemic control ${ }^{(35)}$, however further research in this area is required to fully elucidate the mechanisms for this potential hypothesis.

\section{Strengths and limitations}

Our study had many strengths in that it was a comprehensive longitudinal follow-up study with detailed measures of child growth and body composition taken at multiple ages in early childhood. These anthropometric measures, for both mother and child, were carried out by trained healthcare professionals, rather than based on self-reported measures. We collected information on maternal protein intakes during each trimester of pregnancy, that allowed us to examine the importance of timing of nutrient exposure on the fetus. We also took two different approaches to examine maternal intakes of protein; as a percentage of total energy and in proportion to maternal weight status, as per dietary guidelines for protein. These different approaches may have allowed us to more comprehensively decipher the relationship between protein intake and child growth velocity. Some limitations exist; the anthropometric measurements collected at each age primarily assess child weight and adiposity levels, not lean mass. As, potentially, these associations may be related to the muscle mass in the child, we did not have specific measurements to allow us to investigate this in more detail. As with all self-reported food intake methods, there is the risk of participant underreporting with the food diaries, however to attempt to control for this we ran a sensitivity analysis excluding any potential underreporters and this had no impact on our findings. This analysis was carried out using data from a randomised control trial that altered maternal dietary intakes; however, membership of the intervention group was controlled for in all analyses. The average birth weight of the infants was $4.02 \mathrm{~kg}$, which is in the macrosomic range, and every mother in this cohort had previously given birth to a macrosomic infant. While this is a healthy longitudinal cohort and we had a large sample size, this may limit the representativeness of the results to other populations. An important limitation to note was that detailed dietary intakes and physical activity habits during childhood were not available in this cohort, which would be particularly important in terms of 
Protein in pregnancy and childhood growth

Table 5. Multiple linear regression models for maternal protein intakes and child body composition measures

\begin{tabular}{|c|c|c|c|c|c|c|c|}
\hline Model & $B$ & $P$ & $95 \% \mathrm{Cl}$, lower & $95 \% \mathrm{Cl}$, upper & $r^{2}$ adj & $F$ & $P$ \\
\hline \multicolumn{8}{|l|}{6 month weight centile $†$} \\
\hline $\mathrm{T} 1$ weight-adjusted protein ( $\mathrm{g} / \mathrm{d}$ per $\mathrm{kg}$ ) & $-5 \cdot 635$ & 0.433 & $-19 \cdot 805$ & 8.535 & $0 \cdot 162$ & $4 \cdot 885$ & $<0.001$ \\
\hline \multicolumn{8}{|l|}{2 year weight centile† } \\
\hline T1 weight-adjusted protein ( $\mathrm{g} / \mathrm{d}$ per $\mathrm{kg}$ ) & -8.568 & 0.246 & $-23 \cdot 123$ & 5.988 & $0 \cdot 152$ & 4.411 & 0.001 \\
\hline \multicolumn{8}{|l|}{5 year weight centile $(\mathrm{cm}) \dagger$} \\
\hline T1 weight-adjusted protein ( $\mathrm{g} / \mathrm{d}$ per $\mathrm{kg}$ ) & $-21 \cdot 648$ & $0.001^{*}$ & $-34 \cdot 383$ & -8.913 & 0.201 & $6 \cdot 247$ & $<0.001$ \\
\hline \multicolumn{8}{|l|}{ Birth weight centile $(\mathrm{cm}) \ddagger$} \\
\hline T2 weight-adjusted protein ( $\mathrm{g} / \mathrm{d}$ per $\mathrm{kg}$ ) & 0.091 & 0.165 & -0.037 & 0.219 & $0 \cdot 192$ & $17 \cdot 606$ & $<0.001$ \\
\hline \multicolumn{8}{|l|}{2 year weight centile $(\mathrm{cm}) \dagger$} \\
\hline T2 weight-adjusted protein ( $\mathrm{g} / \mathrm{d}$ per $\mathrm{kg}$ ) & -2.095 & 0.774 & $-16 \cdot 474$ & $12 \cdot 284$ & $0 \cdot 143$ & $4 \cdot 162$ & 0.002 \\
\hline \multicolumn{8}{|l|}{5 year weight centile $(\mathrm{cm}) \dagger$} \\
\hline T2 weight-adjusted protein ( $\mathrm{g} / \mathrm{d}$ per $\mathrm{kg}$ ) & $-9 \cdot 087$ & $0 \cdot 193$ & $-22 \cdot 815$ & $4 \cdot 640$ & $0 \cdot 127$ & $3 \cdot 656$ & 0.004 \\
\hline \multicolumn{8}{|l|}{2 year weight centile $(\mathrm{cm}) \dagger$} \\
\hline T3 weight-adjusted protein ( $\mathrm{g} / \mathrm{d}$ per $\mathrm{kg}$ ) & $-3 \cdot 806$ & 0.594 & $-17 \cdot 890$ & $10 \cdot 278$ & $0 \cdot 138$ & $4 \cdot 070$ & 0.002 \\
\hline \multicolumn{8}{|l|}{5 year weight centile $(\mathrm{cm}) \dagger$} \\
\hline T3 weight-adjusted protein ( $\mathrm{g} / \mathrm{d}$ per $\mathrm{kg}$ ) & $-12 \cdot 117$ & 0.066 & $-25 \cdot 067$ & 0.832 & $0 \cdot 145$ & $4 \cdot 346$ & 0.001 \\
\hline \multicolumn{8}{|l|}{5 year sum of skinfold measures $(\mathrm{mm}) \S$} \\
\hline $\mathrm{T} 1$ weight-adjusted protein ( $\mathrm{g} / \mathrm{d}$ per $\mathrm{kg}$ ) & -4.946 & 0.234 & $-13 \cdot 155$ & $3 \cdot 264$ & $0 \cdot 120$ & $1 \cdot 380$ & $0 \cdot 227$ \\
\hline
\end{tabular}

$\mathrm{T} 1$, trimester 1; T2, trimester 2; T3, trimester 3; RCT, randomised control trial.

* Significant at $P<0.05$

$\dagger$ Model adjusted for RCT group, maternal education level, breast-feeding and birth weight centile.

‡ Model adjusted for RCT group, maternal BMI during pregnancy, maternal education level and smoking during pregnancy.

$\S$ Model adjusted for RCT group, maternal education level, breast-feeding, skinfold measures at birth and age at data collection.

growth and health. Future research would benefit by taking this into consideration.

\section{Future research}

Our findings suggest that high maternal protein intake in earlyand mid-pregnancy may have a programming effect on the offspring and result in slower growth rates into early childhood. With recent research focusing on the associations with early childhood protein intake and growth, more focus is needed on dietary protein intakes in pregnancy and the effect this has both in utero and in later childhood. Pregnancy is a time when women have increased interaction with healthcare professionals and the drive for healthy outcomes can be a powerful stimulus in altering food habits and dietary intakes $^{(40)}$. This provides a unique opportunity for interventions which can be aimed at reducing later health risks for the offspring. This may be beneficial in curbing the current childhood obesity crisis and to promote healthier growth patterns. To our knowledge, we are one of the first studies to report that the associations between maternal protein intakes and the resulting child body composition are not mediated by IGF-1. Further research is required to substantiate our findings in additional cohorts and to elucidate the exact mechanisms by which maternal protein intake influences the developing fetus into early childhood.

\section{Conclusion}

We found maternal protein intake was associated with child weight and length up to 5 years of age. Our findings suggest that high protein intake in early-pregnancy may exert an in utero effect on offspring body composition with a higher weight initially at birth, but slower growth rates into childhood.
Protein intakes below IOM recommendations $(1 \cdot 1 \mathrm{~g} / \mathrm{kg}$ per $\mathrm{d}$ in later pregnancy) were associated with higher weights and lengths in early childhood. These associations between prenatal protein intakes and child body composition were not mediated by IGF-1. Further research is needed to investigate how dietary protein modulates fetal growth. With accelerated catch-up growth in early childhood being associated with increased risk of adverse health, these novel findings may be beneficial in curbing the current childhood obesity crisis and in promoting healthier growth patterns. Further research is required to corroborate these findings in additional cohorts and to elucidate the mechanisms by which maternal protein intake influences the developing fetus into early childhood.

\section{Acknowledgements}

The authors would like to thank all the participants from the ROLO study.

This study was supported by the Health Research Board Ireland, the Health Research Centre for Health and Diet Research, The National Maternity Hospital Medical Fund and the European Union's Seventh Framework Programme (FP7/ 2007-2013), project EarlyNutrition under grant agreement no. 289346. The funders had no role in the design, analysis or writing of this article.

F. M. M., E. J. M., M. K. H. and J. D. were responsible for the project conception, A. A. G., G. A., R. S. and F. M. M. designed the research and the analysis plan, A. A. G., E. C. O., M. K. H. and E. L. conducted the research and carried out data collection, J. M. collated the database and computed new data, A. A. G. analysed data and performed statistical analysis with guidance from R. S., A. A. G. wrote the paper, and all authors critically reviewed and approved the final manuscript.

The authors declare that there are no conflicts of interest. 


\section{Supplementary material}

For supplementary material/s referred to in this article, please visit https://doi.org/10.1017/S0007114518002611

\section{References}

1. Vickers MH (2014) Early life nutrition, epigenetics and programming of later life disease. Nutrients $\mathbf{6}, 2165-2178$.

2. Grieger J \& Clifton V (2014) A review of the impact of dietary intakes in human pregnancy on infant birthweight. Nutrients 7, 153-178.

3. Godfrey KM \& Barker DJP (2001) Fetal programming and adult health. Public Health Nutr 4, 611-624.

4. Geraghty AA, Alberdi G, O'Sullivan EJ, et al. (2016) Maternal blood lipid profile during pregnancy and associations with child adiposity: findings from the ROLO study. PLOS ONE 11, $1-13$.

5. Yang Z \& Huffman SL (2013) Nutrition in pregnancy and early childhood and associations with obesity in developing countries. Matern Child Nutr 9, 105-119.

6. Van Abeelen AFM, Elias SG, Bossuyt PMM, et al. (2012) Famine exposure in the young and the risk of type 2 diabetes in adulthood. Diabetes 61, 2255-2260.

7. Navarro E, Funtikova AN, Fíto M, et al. (2017) Prenatal nutrition and the risk of adult obesity: long-term effects of nutrition on epigenetic mechanisms regulating gene expression. $J$ Nutr Biochem 39, 1-14.

8. Butte NF, Wong WW, Treuth MS, et al. (2004) Energy requirements during pregnancy based on total expenditure and energy deposition. Am J Clin Nutr 79, 1078-1087.

9. Kalhan SC (2000) Protein metabolism in pregnancy. Am J Clin Nutr 71, 1249S-1255S.

10. WHO/FAO/UNU Expert Consultation (2007) Protein and amino acid requirements in human nutrition: report of a joint FAO/WHO/UNU expert consultation. World Health Organ Tech Rep Ser 935, 1-265.

11. Institute of Medicine Food and Nutrition Board (2005) Dietary Reference Intakes: Energy, Carbohydrates, Fiber, Fat, Fatty Acids, Cholesterol, Protein, and Amino Acids. Washington, DC: National Academies Press.

12. McGowan C, Walsh J, Byrne J, et al. (2010) Nutrient intakes during early pregnancy of women living in Ireland. Proc Nutr Soc 69, E344.

13. Stephens TV, Payne M, Ball RO, et al. (2014) Protein requirements of healthy pregnant women during early and late gestation are higher than current recommendations. J Nutr 145, 73-78.

14. Lundqvist A, Johansson I, Wennberg A, et al. (2014) Reported dietary intake in early pregnant compared to non-pregnant women - a cross-sectional study. BMC Pregnancy Childbirth 14, 373 .

15. Mouratidou T, Ford F, Prountzou F, et al. (2006) Dietary assessment of a population of pregnant women in Sheffield, UK. Br J Nutr 96, 929-935.

16. Liberato SC, Singh G \& Mulholland K (2013) Effects of protein energy supplementation during pregnancy on fetal growth: a review of the literature focusing on contextual factors. Food Nutr Res 57, 10.3402/fnr.v57i0.20499.

17. Imdad A \& Bhutta ZA (2011) Effect of balanced protein energy supplementation during pregnancy on birth outcomes. BMC Public Health 11, S17.

18. Ota E, Tobe-Gai R, Mori R, et al. (2015) Antenatal dietary advice and supplementation to increase energy and protein intake. Cochrane Database Syst Rev, issue 6, CD000032.
19. Putet G, Labaune J-M, Mace K, et al. (2016) Effect of dietary protein on plasma insulin-like growth factor-1, growth, and body composition in healthy term infants: a randomised, double-blind, controlled trial (Early Protein and Obesity in Childhood (EPOCH) study). Br J Nutr 115, 271-284.

20. Koletzko B, von Kries R, Closa R, et al. (2009) Lower protein in infant formula is associated with lower weight up to age 2 y: a randomized clinical trial. Am J Clin Nutr 89, 18361845.

21. Inostroza J, Haschke F, Steenhout P, et al. (2014) Low-protein formula slows weight gain in infants of overweight mothers. J Pediatr Gastroenterol Nutr 59, 70-77.

22. Smith W, Underwood L \& Clemmons D (1995) Effects of caloric or protein restriction on insulin-like growth factor-I (IGF-I) and IGF-binding proteins in children and adults. J Clin Endocrinol Metab 80, 443-449.

23. Kadakia R, Ma M \& Josefson JL (2016) Neonatal adiposity increases with rising cord blood IGF-1 levels. Clin Endocrinol (Oxf) 85, 70-75.

24. De Jong M, Cranendonk A, Twisk JWR, et al. (2017) IGF-I and relation to growth in infancy and early childhood in verylow-birth-weight infants and term born infants. PLOS ONE 12, e0171650.

25. Walsh JM, McGowan CA, Mahony R, et al. (2012) Low glycaemic index diet in pregnancy to prevent macrosomia (ROLO study): randomised control trial. Br Med J 345, e5605e5605.

26. Horan MK, McGowan CA, Gibney ER, et al. (2014) Maternal low glycaemic index diet, fat intake and postprandial glucose influences neonatal adiposity - secondary analysis from the ROLO study. Nutr J 13, 78.

27. Horan MK, McGowan CA, Gibney ER, et al. (2014) Maternal diet and weight at 3 months postpartum following a pregnancy intervention with a low glycaemic index diet: results from the ROLO randomised control trial. Nutrients 6, 29462955.

28. McGowan CA, Walsh JM, Byrne J, et al. (2013) The influence of a low glycemic index dietary intervention on maternal dietary intake, glycemic index and gestational weight gain during pregnancy: a randomized controlled trial. Nutr J 12, 140.

29. Cole T, Freeman J \& Preece M (1995) Body mass index reference curves for the UK, 1990. Arch Dis Child 73, 25-29.

30. Pan H \& Cole T (2012) LMS growth, a Microsoft Excel add-in to access growth references based on the LMS method. Version 2.77. http://www.healthforallchildren.com (accessed March 2017).

31. Hayes AF (2012) PROCESS: A Versatile Computational Tool for Observed Variable Mediation, Moderation, and Conditional Process Modeling (White paper). http://www.afhayes. $\mathrm{com} /$ public/process2012.pdf

32. Goldberg G, Black A, Jebb S, et al. (1991) Critical evaluation of energy intake data using fundamental principles of energy physiology: 1. Derivation of cut-off limits to identify underrecording. Eur J Clin Nutr 45, 569-581.

33. McGowan CA \& McAuliffe FM (2012) Maternal nutrient intakes and levels of energy underreporting during early pregnancy. Eur J Clin Nutr 66, 906-913.

34. Switkowski KM, Jacques PF, Must A, et al. (2016) Maternal protein intake during pregnancy and linear growth in the offspring. Am J Clin Nutr 104, 1128-1136.

35. Andreasyan K, Ponsonby A-L, Dwyer T, et al. (2007) Higher maternal dietary protein intake in late pregnancy is associated with a lower infant ponderal index at birth. Eur J Clin Nutr 61, 498-508.

36. Borazjani F, Angali KA \& Kulkarni SS (2013) Milk and protein intake by pregnant women affects growth of foetus. $J$ Heal Popul Nutr 31, 435-445. 
37. Tielemans MJ, Steegers EAP, Voortman T, et al. (2007) Protein intake during pregnancy and offspring body composition at 6 years: the Generation R Study. Eur J Nutr 56, 2151-2160.

38. Barker DJP, Osmond C, Forsén TJ, et al. (2005) Trajectories of growth among children who have coronary events as adults. $N$ Engl J Med 353, 1802-1809.
39. Chomtho S, Williams JE, Lucas A, et al. (2008) Infant growth and later body composition: evidence from the 4-component model. Am J Clin Nutr 87, 1776-1784.

40. O'Brien OA, Lindsay KL, McCarthy M, et al. (2017) Influences on the food choices and physical activity behaviours of overweight and obese pregnant women: a qualitative study. Midwifery 47, 28-35. 